\title{
Experiencing the AI emergence in Indian retail - Early adopters approach
}

\author{
R. Seranmadevi ${ }^{a^{*}}$ and A. Senthil Kumara
}

${ }^{a}$ School of Commerce Studies, Jain Deemed-to-be-University, Bengaluru, Karnataka, India

\begin{tabular}{l}
\hline C H R O N I C L E \\
\hline Article history: \\
Received: September 5, 2018 \\
Received in revised format: Octo- \\
ber 8, 2018 \\
Accepted: November 1, 2018 \\
Available online: \\
November 1, 2018 \\
\hline Keywords: \\
Artificial intelligence \\
Big data \\
Consumer delight \\
Offline \\
Online \\
Retail \\
Retailers intention
\end{tabular}

\section{A B S T R A C T}

\begin{abstract}
The usage of Artificial Intelligence (AI) technique under retail industry will bring glorious outcome and flourishing benefits for both the retailers and the distinguished customers. The multiple platforms of AI usage in retail arena are discussed under two different cluster classified as online and offline, based on the terms of execution of retail activity. The present research was conducted with the objectives of evaluating the contribution of quality, customer relationship management and big data in designing futuristic retail model and analyzing the intention of retailers and shoppers in experiencing the emergence of AI. Disproportionate multistage judgement sampling method was employed. A sample of 610 shoppers from four different capital regions of southern part of states in India was considered for the statistical analysis. Data was collected during the first quarter period of 2018. Descriptive research design was used to describe the intention of shoppers towards the emergence of AI in the Indian retail sector. The usages of AI technologies in online and offline retail are grouped separately and its effect on building the quality, customer relationship management and big data was evolved. Finally, its impact on the retailers intention and customers delight was studied through Structural Equation Modeling with testing of appropriate hypothesis.
\end{abstract}

C 2019 by the authors; licensee Growing Science, Canada

\section{Introduction}

The retail sector in the world is debatably in a considerable state of change and retail business transformation. The entire retail industry is trying to cope with fast-changing customer shopping insights and giving importance for shifting the conventional trading to the web. According to the report of Infosys (2017), Retail sector has invested more amounts for supply chains to become more web-centric and the variety of technologies including Artificial Intelligence (AI), robotics, logistics automation, data analytics and self-service technologies in an effort to become more competitive, more customer-centric and more responsive demand and opportunity. According to Amrita Nair-Ghaswalla (2018), retail giants such as Amazon, Walmart and Starbucks and few other brands are rapidly renovating their retail sector through technology advancements, and these are turning to augmented reality, facial recognition, staffless trading and virtual apps to boost their marketing. Artificial Intelligence User Interface (AIUI) helps the retailer decide what to display, order and when, what products / services to merchandise at the front of the retail store, or home page of their web site / blogs, provide opportunities of cross-selling and upselling to customers based on prior purchases and current basket contents, the list goes on. AIUI also 
facilitates the businesses and consumers will get benefitted from reduced costs of staff and inventory, improved efficiency and more choices. This is the era of 'always on' consumers, who is changing faster than ever. Consumers require connected and seamless experiences that make their lives easier. There are gaps to be bridged to obtain the benefits of AI on a large scale. For instance, there is a lack of broad based expertise in research and application ("Use of AI", 2018).

\section{Impact of AI in Retail sector}

Retailers have entered the big data era. According to Mills et al. (2012) and Sicular (2013), Big data is a term that is used to describe data that in high volume, high velocity, and high variety; requires new technologies and techniques to capture, store, and analyze it; and is used to enhance decision making, provide insight and discovery, and support and optimize processes. Businessmen / artificial intelligence use customer details in big data that comes from a variety of emerged sources, including social media, machines learning, audio and video files, the data browsed in the web, facial recognition, text, image, RFID, and Global Positioning System (GPS). Further, these sources have strained in traditional relational database management systems for producing a number of new technologies, approaches, and platforms. The success of big data analysis process depends on the use of right analytical tools and people skilled in the use of analytics (Watson, 2014). As shown in Fig. 1, AI and its algorithm based sub branches such as machine learning, deep learning, neural networks often use the big data for producing the desired results for the retailers and shoppers. Usages of mobile phones by consumers for retail purpose are the important source for big data. Because of the paradigm shift in the customized data process, big data plays an important role in fourth generation of decision support data management especially in online companies like Google and Facebook. Big data can supply real customer insights and hence helps retailers suggest more personalized offering and customer services in offline as well as online.

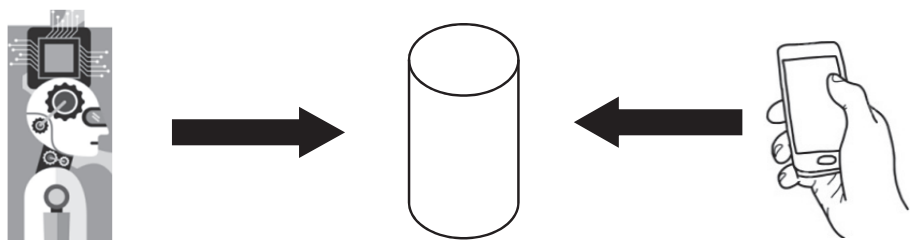

Artificial Intelligence Big Data Consumer

Fig. 1. Big Data in Retail

The shopping venues are becoming dynamic and environments which are relying on sensors to capture data and making intelligent analysis on real time during consumer's shopping experience. These shopping stores are delivering richer in-store experiences by implementing emerging AI technologies. Recently huge investments are made by retailers and technology industry players on AI tools to optimize their business functions and automate supply chain scenarios. The technology giants like Apple, Google and Facebook are implementing the concepts of AI and Machine Learning (ML) extensive than ever before (Technology Trends, 2017). The Radio-frequency identification (RFID) enabled technology helps to see all product features and information such as price, size, color, fabric, washes, weight, etc. on the RFID-enabled digital screen and one can see how it looks on studio image models wearing them. There are offline standalone stores having virtual reality zone, a video wall with a multi touch interface for product discovery, less or without staff and self-checkouts within five minutes. In recent years the Google and Amazon are spending heavy bucks on making virtual assistants as smart as a human being. They are getting profit through advertising and it's all about the outcome of data they have about customers. 
The AIUI technology facilitates the retailers to adopt the up-selling and cross-selling practices through which it induces the shoppers to buy comparable higher-end products and related items. About 70 per cent of the Generation $\mathrm{Z}$ customers are more likely to visit stores with interactive experiences. By 2020, 85 per cent of customer-enterprise relations will exclude human interaction. At present Mobile Point of Sale (M-POS), Auto billing, Virtual Assistant, managing shopping profile, interacting through hologram window, touch screen display and self checkout are the emerging AIUI technologies which are using in offline retail sector. The application of AI technology promotes staffless and stockless retail trading. Staffless is a form of organizational structure where the system allows unmanned or semi-manned retail stores. The staffless retail store is an automated retail system that allows convenience store operators to remove all or most of the labours while significantly reducing theft. Unmanned store allows the customer Do it Yourself (DIY) shopping. The most significant exercise for physical retailers is restocking and managing inventory. Unmanned stores offer more cost-effective and efficient ways to restock. Instead of human employees, retailer use sensors and data analytics software to track inventory. When stock runs low, the self-driving vehicle can simply return to the warehouse to replace the entire shelving unit with a full one. Recently, retailers are restructuring their operations to embrace automation using robots. The robot maneuvers freely around the store, looking for out-of-stock items. It then reports data to the store's backend operations to replenish missing items. This process can be called as stockless trading. Real time information are provided to robot to make easier for people to do their jobs and keep shelves full for customers.

\section{Review of Literature}

As recent independent research conducted by Infosys (2017) in retail sector found that retailers have been using AI systems as part of their operations for an average of two years, with 44 per cent using AI technology for between one and three years, with a further 20 per cent actively using AI for over five years. Overall, 87 per cent of retailers surveyed have deployed a part of AI or automation process as part of their retail activities and decision-making processes.

Lee et al. (2017) conducted a research to investigate the influences among product attributes, product involvement, word-of-mouth, and purchase intention toward medical equipment in online shopping. The study result found that the factors including product information, product price, product involvement and word-of-mouth have positive impacts on purchase intention, whereas product quality had no effects on purchase willingness. As source of study by Imagica (Brand Wagen, 2018) entitled "Consumer's Leisure Behaviour" says that smartphones play a vital role to use the internet and user friendly rather than laptop or desktop PCs. The study also found that 71 per cent are using internet for social media and 40 to 45 per cent are using internet for shopping or bookings and 44 per cent are using internet for financial transactions. On average 94 per cent are using smartphone for accessing internet. Cognizant's recent report on retail (Amrita, 2018) says that emerging economic and revenue models are paving the way for a rewired retail experience and the retailers focusing on omni channel / unified commerce for increasing their profits. Instant satisfaction will be the path to providing it. Supporting to this statement, very big retail giants such Alibaba, Amazon etc. are adopting AIUI model in offline as well as online for effective shoppers' experience (Sindhu, 2018a). Harvard Business Review (Juan Pablo Vazquez Sampere, 2014), says Alibaba brings completely a different retail model Online to Offline Commerce (O2O) by investing \$300 million in Bigbasket, an online grocery store in India. Nearly 300 start-ups in India are using AI in any one of the forms in various industries, of which 29 per cent start-ups are focusing on finding solution for the problems in the retail sector, a report by Kallari Capital (Technology Trends, 2017). The study of various researches of AI emergence in Indian retail sector raises the following questions: a) how well the techniques of AI contributes the online and offline retailing in India b) whether these techniques will promote the quality, customer relationship management and manage the big data for decision making process and c) what is the intention of early adopters while experiencing the AI emergence in Indian retail. 


\section{Research Objectives}

To find answers to the above questions raised, the present study has been conducted with the following objectives:

1) To study the factors contributing the online and offline retailing under AI era,

2) To evaluate the contribution of quality, customer relationship management and big data in designing futuristic retail model,

3) To analyse the intention of retailers and shoppers in experiencing the emergence of AI.

\section{Research Methodology}

Disproportionate multistage judgement sampling techniques has been employed to collect the data from 610 shoppers located at four capital regions viz Chennai, Thiruvananthapuram, Bengaluru and Hyderabad of southern part of states in India such as Tamilnadu, Kerala, Karnataka and Telangana respectively. Hair et al. (1998) proposed that with quantitative research, as a minimum 100 respondents should be considered in order to carry out the statistical analysis. Data was collected during first quarter period of the year 2018. The primary data were collected from the shoppers of the above four cities through structured questionnaire processed in online mode. Since the study is based on early adopters approach though the invention of AI technologies is largely available only at the capital region of these states rather than the penetrated region. Descriptive research design is used to describe the intention of shoppers' purview towards the emergence of AI in the Indian retail sector. The study is limited to southern part of India and it covered capital city of four states alone. The sample is limited to 610 respondents. The appropriate statistical methods and tools had been used in the study to arrive at the findings. The usages of AI technologies in online and offline retail are grouped separately and its effect on building the quality, CRM and big data was evolved. Further, its impact on the retailers intention and customers delight are studied through Structural Equation Modeling using AMOS software V.20and it was tested with the appropriate hypothesis.

\section{Research Discussion}

\subsection{Impact of usage of Artificial Intelligence Techniques in achieving Retailers Intention and Consumer Delight}

The usage of Artificial Intelligence Technique under Retail industry will bring glorious outcome and flourishing benefits for both the retailers and the distinguished customers. The way of deployment of AI technologies in both online retailing in terms of e-commercial activity and off line retailing in terms of legacy store operations was assumed as the independent variables and the effect of the usage of AI technologies are further involved in turning the daily commercial transaction happened in both online and offline as a big volume of database, which will tends to serve as a huge value assets and authenticated resource to predict the future progress of retail industry as well.

The day-to-day transactions happened in the retail industry was minutely observed and stored in the database, based on the requirement of the customers the retailers tend to build up the rapport with their customers by fulfilling their requests even before they are declared to the retailers. The past purchase history of the respective customers and their intention towards different products, how long they have spent time with particular category of the products, their eye-ball movements, search requests, and so on are used to evaluate the interest of the particular customer, and whenever the product they have been searched and indulge to buy are readily available at the store, then the message will fired in their communication devices thereof as a signal of alertness. These kinds of attractions and rapports can be devel- 
oped by the retailers only after the intervention of the AI technologies in retail sector. The multiple platforms of AI usage in retail arena are discussed under two different clusters classified as online and offline, based on the terms of execution of retail activity.

In Online retail mode, of course enormous tools of AI was already employed to observe the customers on their every click. The AI technology sometimes worked at the backdrop to collect, store and disseminate the information about the customers and helps to build Big data and supports Big data analytics. At the same time, the AI technology has shown it's another face at the front line operations of the retail industry, in product demonstration and display, cart operations and stores management and relationship management. The following are the factors have been enumerated as the usage of AI technologies under the online cluster, namely Virtual Reality, Voice Recognition Technology (VRT), Augmented Reality, Customized assistant, Carrier billing, Review mechanism, Product Comparison, Massive information, and Intuitive signals. The way how the AI technologies deployed in offline cluster are Cross selling, Up selling, M-POS (Mobile Point of Sales), Auto billing, Shoppers' profile, Self-checkout, Virtual assistant, Hologram window and Feel of touch. The usage of AI technologies in online and offline retail are enhancing the retailers to engrave the quality of operations, explore the wide range of Customer Relationship Management (CRM), and assisted vigorously to build the Big data base, tends to explore the different profile of the customers, buying pattern, seasonal variation in sales and promo combo effectiveness, impact of advertisement, cause of impulse buying, attracting factors of customers, sales charts, inventory procurement and maintenance based on requirement, assortment collection, category management, etc., in all the nook and corner of the retail and customer enlighten actions.

By affording the cost of implementation of AI technologies into the retail parlance, all the other costs associated with labour, material procurement, maintenance of safety and buffer stock limit, EOQ determination, Costing department, Assortment Collection, Variety management and even the cost required to make arrangement of visual display and visual presentation of the assortments in retail store and so are quite vanished off. Moreover, the AI technologies done majority loading and de-loading of assortment at the aisles in case of offline retailing, maintaining relationship with supplier arrangements and logistics management as in the case of online retailing cluster. The customers are ultimately benefited through their Paradigm shift exhibited in their life style changes and especially Exhilaration of enjoying the new advent technologies in to their daily operations.

The advent of AI technologies into retail sector in both online and offline cluster through different modes are categorized and presumed as the independent variables for the study. The quality of retail operations, construction of Big data base and engraving the customer relationship management through AI technologies are considered to be the mediating variables in order to evaluate the impact of usage of AI technologies in escalating retailers benefits and customers enchantment. In developing the model for evaluating the impact of usage of Artificial Intelligence in retail sector, the outcome variables are Retail intention to go with Staff less and Stockless and the achieving the customers delight by paradigm shift in their life style behavior and providing the exhilaration for developing good harmony with the retailers.

The model is built to explain the relationship among the online and offline usage of Artificial intelligence technologies and its impact on measuring the retailers' intention and customers' delight. There are 25 endogenous variables and 27 Unobserved, endogenous variables are used to construct the following model. Among the 25 observed cum endogenous variables nine variables are pertaining to the usage of AI technologies in Online mode and the other nine variables are connected to the use of AI technologies in offline mode and the rest of seven variables are moderating and latent variables namely Quality, CRM and Big data and the outcome variables staffless, stockless, paradigm shift and exhilaration of customers.

The usage of AI technologies in online are clustered separately and offline are grouped separately and its effect on building the quality, customer relationship management and big data base was evolved, finally its impact on the retailers intention and customers delight are studied through constructing model using 
AMOS software V.20. Among the 27 unobserved and endogenous variables, 25 are the error variables and two variables are the grouping variables for the outcome variables one in retailers' intention, it is used to group the staffless and stockless and the other one customer delights is grouping the paradigm shift and exhilaration of the customers. The measurement model was constructed using the AMOS software and the same was displayed in Fig. 2. The measurement model attempts to describe the various components of online retail trading and the apparatuses being constituted the offline retail platform. Further, it derived the relationship of both of these online and offline retail mode with the Quality of transactions, establishment of Customer Relationship Management, construction of Big data base. Moreover, the measurement model explains the relationship between Quality, CRM and Big data with Retailers Intention towards Staffless and Stockless behavior and ultimately the achievement of customer delight through proving improved life style by paradigm shift in their buying behavior and the Exhilaration in experiencing the different retail avenue.

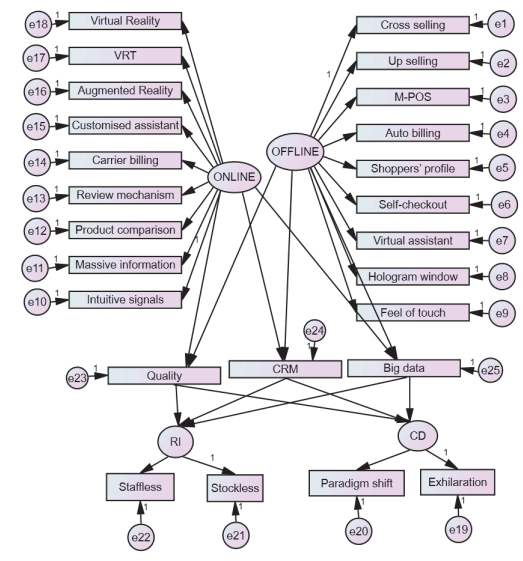

Fig. 2. Measurement model for Usage of AI technologies in Retail user Interface

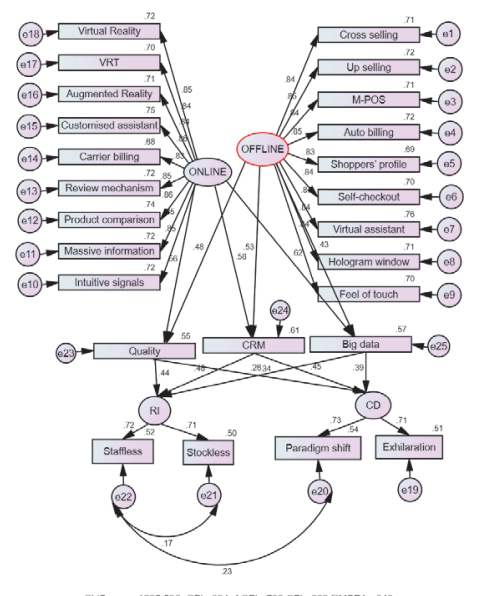

Fig. 3. Structural model for Usage of AI technologies in Retail user Interface

The model was constructed through confirmatory factor analysis and the statistical result was observed. To get the model more reliable and consistent, the recommendations given by the modification indices under the confirmatory factor analysis are incorporated promptly with logical sense and finally arrived with the structural model with best fit. The statistical result observed after performing the confirmatory factor analysis and the observed estimates for the different relationship among various factors used to construct the model with standardized and unstandardized estimates level are well depicted through the following Table 1.

From the standardized estimate analysis it was observed that, the relationship among the factors used to construct the model is highly significant with $\mathrm{p}$ value less than .05 . To explore further, the relationship between various apparatuses of offline retail mode are Cross selling (.72); Up selling (.70); M-POS (.71); Auto billing (.75); Shoppers' profile (.68); Self-checkout (.72); Virtual assistant (.74); Hologram window (.72); Feel of touch (.72). The statistical results reveal the expectations of the customers to make the offline retailing more better progress, Auto billing stands at the first position in influencing the offline retail mode, since the shoppers are highly disappointed with the billing process and queuing system adopted in the Indian retail scenario. The shoppers need to conserve their valuable time and not ready to spend idly at the billing counter. The shoppers are encouraging the cross selling, self-checkout and feel of touch in offline mode to continue further and expecting the new invented technology like Virtual Assistant, Hologram Window, and so on to improve the offline retail grade as one step ahead of traditional methods. 
Table 1

Standardized Estimate Results

\begin{tabular}{|c|c|c|c|c|c|c|c|c|}
\hline Variables & & Variables & $\begin{array}{l}\text { Unstandardized Esti- } \\
\text { mates }\end{array}$ & $\begin{array}{l}\text { Standardized Esti- } \\
\text { mates }\end{array}$ & S.E. & C.R. & $\mathrm{P}$ & $\mathrm{R} 2$ \\
\hline Ouality & $\leftarrow$ & OFFLINE & .453 & .484 & .041 & 10.994 & $* * *$ & .48 \\
\hline Quality & $\leftarrow$ & ONLINE & .547 & .563 & .044 & 12.497 & $* * *$ & .56 \\
\hline Big data & $\leftarrow$ & ONLINE & .600 & .619 & .044 & 13.623 & $* * *$ & .62 \\
\hline Big data & $\leftarrow$ & OFFLINE & .402 & .429 & .040 & 10.037 & $* * *$ & .43 \\
\hline CRM & $\leftarrow$ & ONLINE & .575 & .576 & .043 & 13.382 & $* * *$ & .58 \\
\hline CRM & $\leftarrow$ & OFFLINE & .508 & .527 & .041 & 12.418 & $* * *$ & .53 \\
\hline RI & $\leftarrow$ & Quality & .330 & .441 & .044 & 7.527 & $* * *$ & .44 \\
\hline $\mathrm{CD}$ & $\leftarrow$ & Quality & .267 & .339 & .041 & 6.493 & $* * *$ & .26 \\
\hline $\mathrm{CD}$ & $\leftarrow$ & Big data & .311 & .395 & .042 & 7.450 & $* * *$ & .39 \\
\hline $\mathrm{CD}$ & $\leftarrow$ & CRM & .342 & .446 & .042 & 8.170 & $* * *$ & .45 \\
\hline RI & $\leftarrow$ & CRM & .347 & .477 & .044 & 7.918 & $* * *$ & .48 \\
\hline RI & $\leftarrow$ & Big data & .192 & .257 & .043 & 4.502 & $* * *$ & .34 \\
\hline Off1 & $\leftarrow$ & OFFLINE & 1.000 & .845 & & & & .72 \\
\hline Off2 & $\leftarrow$ & OFFLINE & .975 & .846 & .052 & 18.859 & $* * *$ & .70 \\
\hline Off3 & $\leftarrow$ & OFFLINE & 1.000 & .844 & .053 & 18.783 & $* * *$ & .71 \\
\hline Off4 & $\leftarrow$ & OFFLINE & .994 & .851 & .052 & 19.078 & $* * *$ & .75 \\
\hline Off5 & $\leftarrow$ & OFFLINE & .967 & .831 & .053 & 18.298 & $* * *$ & .68 \\
\hline Off6 & $\leftarrow$ & OFFLINE & .981 & .839 & .053 & 18.610 & $* * *$ & .72 \\
\hline Off7 & $\leftarrow$ & OFFLINE & 1.054 & .873 & .053 & 19.961 & $* * *$ & .74 \\
\hline Off8 & $\leftarrow$ & OFFLINE & .994 & .845 & .053 & 18.818 & $* * *$ & .72 \\
\hline Off9 & $\leftarrow$ & OFFLINE & .979 & .836 & .053 & 18.483 & $* * *$ & .72 \\
\hline ON9 & $\leftarrow$ & ONLINE & 1.000 & .848 & & & & .70 \\
\hline ON8 & $\leftarrow$ & ONLINE & 1.016 & .848 & .053 & 19.078 & $* * *$ & .71 \\
\hline ON7 & $\leftarrow$ & ONLINE & 1.051 & .858 & .054 & 19.481 & $* * *$ & .76 \\
\hline ON6 & $\leftarrow$ & ONLINE & 1.016 & .846 & .053 & 19.007 & $* * *$ & .70 \\
\hline ON5 & $\leftarrow$ & ONLINE & .921 & .825 & .051 & 18.213 & $* * *$ & .69 \\
\hline ON4 & $\leftarrow$ & ONLINE & 1.074 & .863 & .054 & 19.708 & $* * *$ & .72 \\
\hline ON3 & $\leftarrow$ & ONLINE & 1.027 & .840 & .055 & 18.794 & $* * *$ & .71 \\
\hline ON2 & $\leftarrow$ & ONLINE & .987 & .839 & .053 & 18.741 & $* * *$ & .72 \\
\hline ON1 & $\leftarrow$ & ONLINE & .991 & .847 & .052 & 19.068 & $* * *$ & .71 \\
\hline $\mathrm{CD} 2$ & $\leftarrow$ & $\mathrm{CD}$ & 1.000 & .714 & & & & .54 \\
\hline CD1 & $\leftarrow$ & $\mathrm{CD}$ & .979 & .732 & .076 & 12.801 & $* * *$ & .51 \\
\hline RI2 & $\leftarrow$ & RI & 1.000 & .707 & & & & .52 \\
\hline RI1 & $\leftarrow$ & RI & 1.001 & .721 & .073 & 13.677 & $* * *$ & .50 \\
\hline $\begin{array}{l}\text { Virtual Reality } \\
\text { (ON5); Revie } \\
\text { (OFF1); Up s } \\
\text { (OFF7); Holo } \\
\text { Retailers Inten }\end{array}$ & (1) & $\begin{array}{l}\text { ce Recogn } \\
\text { (ON6); } \mathrm{Pr} \\
\text {; M-POS }\end{array}$ & $\begin{array}{l}\text { hnology (ON2); } \\
\text { omparison (ON7) } \\
\text { Auto billing (OF) } \\
\text { uch (OFF9); Staf }\end{array}$ & $\begin{array}{l}\text { nted Reality (ON } \\
\text { ive information (C } \\
\text { hoppers' profile ( } \\
\text { RI1); Stockless (R }\end{array}$ & $\begin{array}{l}\text { omise } \\
\text { d Intu } \\
\text { Self-cl } \\
\text { adigm }\end{array}$ & $\begin{array}{l}\text { sistant (C } \\
\text { signals } \\
\text { out (OFF } \\
\text { ft (CD1) }\end{array}$ & $\begin{array}{l}\text { 4); C } \\
\text { N9); } \\
\text {; Virt }\end{array}$ & . \\
\hline
\end{tabular}

The expectations of retailers and shoppers towards the components of online retail mode are explaining the strong relationship to construct the online retail system. The relationship among the components of online retail models are Virtual Reality (.71); Voice Recognition Technology (.72); Augmented Reality (.71); Customized assistant (.72); Carrier billing (.69); Review mechanism (.70); Product Comparison (.76); Massive information (.71); and Intuitive signals (.70). The shoppers are massively used the product comparison when doing online shopping, thus it stands at the first position. The customized assistant extended by the online shopping to trace the product based on the individual requirements are rated high by the shoppers next to product comparison. Voice Recognition Technology, availability of Massive Information in online and Review Mechanisms also be highly preferred in the next order by the shoppers. The advent of new technology and amalgamated in online shopping like Virtual reality, Augmented reality and Intuitive signals also be highly expected by the shoppers to improve the grade of online shopping experience. The relationship between online shopping and the shoppers' expectations are explained to the Quality (.56); CRM (.58) and Big data (.62). It is understood that from the statistical value, through online shopping mode it yields more data about the shoppers profile to predict the future sale through constructing the Big data base and the Customer relationship management concept was not exposed as much as the offline trading, moreover the shoppers are not having confident over the quality of the product bought through online retail mode, hence it explains the low relationship in explaining the quality 
aspects of online retail mode. The quality (.48), CRM (.53) and Big Data (.43) are explained by the offline retail components. The Customer relationship Management was secured the maximum relationship in offline than the online retail mode and particularly in constructing the Big data base with the shoppers information to design and forecast the future sales progress is very much less effective in offline retail mode. The Quality components are contributing towards the Retailers Intention (.44) and Customer Delight (.26). It is crystal clear that Quality does not influence the customer delight much irrespective of both online and offline retail mode. The Retailers Intention also was not explained to the expected level of Quality in reflecting both online and offline retail mode. The shoppers feel to certain extend of satisfaction through the offline retail customer Relationship Management but again the retailers part of satisfaction has necessarily be improved in order to cover the prospective buyers to project their sales in future. The construction of Big data base is helpful to the Retailers Intention (.34) and Customer delight (.39). The data collected from the shoppers has to be further utilized by the retailers in an extensive way. Here especially in India, the condition is exposing the different scenes, the time, cost and effort are completely and dedicatedly spent by the retailers with the intention to collect the shoppers' details both from online and offline mode. Besides, the usage of those data for further productive purpose is not flourished to the expected level. The data analyst are not sufficient to project the data in different dimension to benefit both the retailers and shoppers in developing the future shopping experience in the next level. The awareness of data collection was popularized among the retailers also the usage has to be improved, then only both the retailers and shoppers will taste the real benefit of it. From the basic expectations of shoppers from both online and offline are derived to frame out the retailers intention to cost conservation through the staff less and stock less mode. The staff less retailing (.52) and stock less retailing (.50) gained moderate importance. The retailers are planned to reduce the man power involvement in maintaining the stock keeping unit, assortments collection, arrangement of merchandise and planograms etc., instead, they focused to bring the Artificial Intelligence Technology to replace the man power. The Artificial Intelligence (AI) Technology will enhance the retailers to maintain the stock Keeping unit for every individual items, helps to maintain the assortment collections based on the customized requirements of the shoppers, fill and refill the stock at the aisles, and helping the shoppers to trace their required products at all the times, and so on. The retailers another great intention is to restrict the deployment of capital in the stock, hence they want to invest only to the category which are highly preferred by the shoppers time- to- time. Unnecessary lock of investment in stock is assumed to be the dead capital, because the change in fashion, trend, style, taste and preference of the shoppers will make retailers position into trouble. Hence it is very much important as in the part of retailer to decide where to invest, how much to invest and how to invest. The tools connected to Artificial Intelligence techniques will assist the retailers to get answers for all these hypothecated questions through previous experience and data analytics.

Nevertheless of the retailers' service, assortment collection, category management, advent of technology the level of customer satisfaction cannot be judged easily. The customer delight under this model is evaluated through two different components that is paradigm shift and exhilaration. Now-a-days shoppers are not interested to waste their time in mere shopping or else they need some indication whenever the required products are readily available at the store to effect immediate purchase with no more time delays. Even some other shoppers are like to do the shopping at their living rooms at a most realistic way. The shoppers expectations are crossed the limit of convenient shopping and it travel towards the zeal of the experienced shopping at their ease. The advent of New technology will always prove to extend the shoppers expectation in all the means and ways of their shopping behavior, hence the shoppers are likely to move from the tradition way of shopping into online mode but without leveraging the flavour of tradition shopping experience, by the way they would not want to miss out the experience of feel of touch, measure the quality and handle the products at the hand, testing the suitability using the trail rooms, and so. The new AI technology provides the chance for all these experiences to the shoppers with the advent of electronic gadgets like head mountain display, trackers and Holograms window. The new experiential way of shopping will influence the shoppers to feel exhilarated and their buying habits are also completely shifted to newer versions. From this model it was concluded that the shoppers are not completely 
gained their delight, because all the technological advancement are not properly be implemented into Indian Retail sector both in Online and offline mode. Table 2 exhibits the statistical results of confirmatory factor analysis for the structural model of Impact of usage of Artificial Intelligence Techniques in achieving Retailers Intention and Consumer Delight. The individual reliability of the items was evaluated using factor loadings (Ce'sar Camiso'n and Ana Villar Lo'pez, 2010). Carmines and Zeller (1979) propagated that the factor loadings should not be less than 0.707 to constitute a valid model. However, some researchers such as Barclay et al. (1995) and Chin (1998) are of the opinion that factor loadings to the extent of 0.5 or 0.6 is acceptable. The confirmatory factor analysis and the structural equation modeling were built based on the hypothesis, there is no significant influence of Quality, Customer Relationship management and Big data on Retailers intention and customer delight.

Table 2

Confirmatory Factor Analysis Result

\begin{tabular}{ll}
\hline Model & Value \\
\hline Chi_Square & 1225.536 \\
P value & .000 \\
GFI & .834 \\
AGFI & .798 \\
CFI & .883 \\
RMR & .061 \\
RMSEA & .040 \\
\hline
\end{tabular}

It was observed that the statistical results of confirmatory factor analysis reveal the required index values and RMR and RMSEA are at the satisfactory level of social science literatures. Hence the constructed structural model was considered as good fit.

Table 3

Testing of Hypothesis for the model

\begin{tabular}{|c|c|c|c|c|c|c|}
\hline \multicolumn{3}{|c|}{ Variables } & Null Hypothesis & $\mathrm{R}^{2}$ & $\mathrm{P}$ & Inference \\
\hline RI & $\leftarrow$ & Quality & There is no influence of quality on Retail Intention & .44 & .032 & Rejected \\
\hline $\mathrm{CD}$ & $\leftarrow$ & Quality & There is no influence of quality on Consumer Delight & .26 & .048 & Rejected \\
\hline $\mathrm{CD}$ & $\leftarrow$ & Big_data & There is no influence of Big data on Consumer Delight & .39 & .036 & Rejected \\
\hline $\mathrm{CD}$ & $\leftarrow$ & CRM & $\begin{array}{l}\text { There is no influence of Customer Relationship Management } \\
\text { on Consumer Delight }\end{array}$ & .45 & .032 & Rejected \\
\hline RI & $\leftarrow$ & CRM & $\begin{array}{l}\text { There is no influence of Customer Relationship Management } \\
\text { on Retail Intention }\end{array}$ & .48 & .022 & Rejected \\
\hline RI & $\leftarrow$ & Big_data & There is no influence of Big data on Retail Intention & .34 & .043 & Rejected \\
\hline
\end{tabular}

It was observed from the above table that quality, Customer Relationship Management and Big data are significantly influence the retailers' intention and customer delight. The results revealed that there was a statistically significant with the reduced $\mathrm{p}$ value less than the .05 , hence it is significant at 95 per cent significant level. Hence the null hypothesis is rejected and concluded that Quality, CRM and Big data have significant influence in determining the Retailers Intention towards the staff less and stock less options and it significantly influences the customers to feel more exhilarated through paradigm shift in their buying behaviour through new experiential shopping vertex.

\section{Conclusion}

The long term role of AI in the retail sector is inevitable. While deployment of AI technologies in offline retails sector, it is necessary to ensure that employees and customers come along for the ride. Since early adopters are experiencing this greater automation AI technologies, the successful implementation of AI in all retail places require balance and equal emphasis on people engagement and skills development. This study found that quality, customer relationship management and big data had significant influence in determining the retailers' intention and customers delight. This research focused only on four capital 
cities of southern states in India and hence the findings are subjected to geographical variations in other parts of the world. As India gets into the AI wave, there is also a need for a robust intellectual property regime. Privacy and security are a major concern as there is no formal regulation in place for anonymisation of data ("Use of AI", 2018). Recently, the retailers are adopting Online-to-Offline (O2O) business strategy in the Indian retail industry where the potential buyers from online channels are to make purchases in physical stores (Sindhu Kashyap, 2018). In future, a research study on this area may be conducted to know the success of this retail strategy.

\section{References}

Amrita, N.G. (2018). Rewiring the shopping experience, Business Line, https://www.thehindubusinessline.com/catalyst/rewiring-the-shopping- experience/article24164899.ece (Accessed 14 June 2018)

Barclay, D., Higgins, C., \& Thompson, R. (1995). The partial least squares (PLS) approach to casual modeling: personal computer adoption and use as an illustration. Technology Studies, 2(2), 285-309.

Brand Wagen (2018) Consumer's Leisure Behaviour. Financial Express, p.3. (Accessed 5 June 2018).

Camisón, C., \& Villar, A. (2009). Capabilities and propensity for cooperative internationalization. International Marketing Review, 26(2), 124-150.

Chin, W. W. (1998). The partial least squares approach to structural equation modeling. Modern methods for business research, 295(2), 295-336.

Carmines, E. G., \& Zeller, R. A. (1979). Reliability and validity assessment (Vol. 17). Sage publications.

Hair, J. F., Tatham, R. L., Andersion, R. E., \& Black W. (1998). Multivariate data analysis. (5th ed.), Prentice-Hall, International, Inc., p.111

Infosys Limited External Document (2017). AI: The Promise of a great future for retailers, Source: Amplifying human potential - towards purposeful artificial intelligence. p.4.

Juan Pablo Vazquez Sampere (2014). Alibaba: The First Real Test for Amazon's ne UsBusiness Model, The HBR Interview, https://hbr.org/2014/01/alibaba-the-first-real-test-for-amazons-business-model (Accessed 1 June 2018).

Lee, W. I., Cheng, S. Y., \& Shih, Y. T. (2017). Effects among product attributes, involvement, word-ofmouth, and purchase intention in online shopping. Asia Pacific Management Review, 22(4), 223-229.

Mills, S., Lucas, S., Irakliotis, L., Rappa, M., Carlson, T., \& Perlowitz, B. (2012). Demystifying big data: a practical guide to transforming the business of government. TechAmerica Foundation, Washington.

Sicular, S. (2013). Gartner's big data definition consists of three parts, not to be confused with three" v" s. Gartner, Inc, 27.

Sindhu, K. (2018a). Alibaba deepens roots in India - what it means for the Indian startup ecosystem. https://yourstory.com/2018/02/alibaba-deepens-roots-india-means-indian-startup-ecosystem/ (Accessed 5 June 2018)

Sindhu, K. (2018b). Online-to-Offline Commerce. https://www.investopedia.com/terms/o/onlinetooffline-commerce.asp (Accessed 10 June 2018)

Technology Trends. (2017) 'Artificial Intelligence - Paving way in Indian Retail Industry' [online]. https://www.fieldassist.in/blog/artificial-intelligence-indian-retail-industry/ (Accessed 11 August 2017)

Use of AI in key sectors will need robust data ecosystem. (2018 June). Business Line, p.7 https://www.thehindubusinessline.com/info-tech/use-of-ai-in-key-sectors-will-need-robust-data-ecosystem-niti-aayog/article24081327.ece (Accessed 10 June 2018)

Watson, H. J. (2014). Tutorial: Big data analytics: Concepts, technologies, and applications. Communications of the Association for Information Systems, 34, 65.

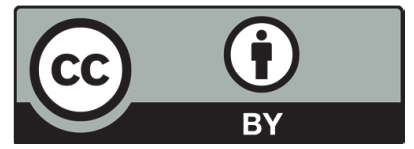

(C) 2019 by the authors; licensee Growing Science, Canada. This is an open access article distributed under the terms and conditions of the Creative Commons Attribution (CCBY) license (http://creativecommons.org/licenses/by/4.0/). 